\title{
Evidence-based selection of environmental factors and datasets for measuring multiple environmental deprivation in epidemiological research
}

\author{
Elizabeth A Richardson*1, Richard J Mitchell ${ }^{2}$, Niamh K Shortt ${ }^{1}$, \\ Jamie Pearce ${ }^{1}$ and Terence P Dawson ${ }^{3}$
}

Address: ${ }^{1}$ School of GeoSciences, The University of Edinburgh, Drummond Street, Edinburgh EH8 9XP, UK, ${ }^{2}$ Section of Public Health and Health Policy, University of Glasgow, 1 Lilybank Gardens, Glasgow G12 8RZ, UK and 33chool of Geography, University of Southampton, Highfield, Southampton SO17 1BJ, UK

Email: Elizabeth A Richardson* - e.richardson@ed.ac.uk; Richard J Mitchell - r.mitchell@clinmed.gla.ac.uk; Niamh K Shortt - niamh.shortt@ed.ac.uk; Jamie Pearce - jamie.pearce@ed.ac.uk; Terence P Dawson - T.P.Dawson@soton.ac.uk

* Corresponding author

from Joint Environment and Human Health Programme: Annual Science Day Conference and Workshop Birmingham, UK. 24-25 February 2009

Published: 21 December 2009

Environmental Health 2009, 8(SuppI I):SI8 doi:I0.II86/I476-069X-8-SI-SI8

This article is available from: http://www.ehjournal.net/content/8/SI/SI8

(C) 2009 Richardson et al; licensee BioMed Central Ltd.

This is an open access article distributed under the terms of the Creative Commons Attribution License (http://creativecommons.org/licenses/by/2.0), which permits unrestricted use, distribution, and reproduction in any medium, provided the original work is properly cited.

\begin{abstract}
This Environment and Human Health project aims to develop a health-based summary measure of multiple physical environmental deprivation for the UK, akin to the measures of multiple socioeconomic deprivation that are widely used in epidemiology. Here we describe the first stage of the project, in which we aimed to identify health-relevant dimensions of physical environmental deprivation and acquire suitable environmental datasets to represent population exposure to these dimensions at the small-area level. We present the results of this process: an evidence-based list of environmental dimensions with population health relevance for the UK, and the spatial datasets we obtained and processed to represent these dimensions. This stage laid the foundations for the rest of the project, which will be reported elsewhere.
\end{abstract}

\section{Introduction}

The physical environment is multifactorial. Environmental factors with health relevance range from pathogenic (i.e., with potential to damage health), to salutogenic (i.e., with potential to enhance or maintain health). Constrained by data limitations and availability, studies of the health effects of the environment often focus on a subset of the environment in isolation [e.g., air pollution: [1]]. However, populations are not exposed to single environ- mental factors in isolation: they simultaneously experience multiple exposures. Evans and Kantrowitz [p.304; [2]] suggest that "... multiple exposures to a plethora of suboptimal environmental conditions" may help explain socioeconomic inequalities in health. Different environmental exposures may have additive, synergistic or antagonistic effects on health when experienced in combination [3], hence identifying areas experiencing multiple environmental deprivation may assist in clarify- 
ing environment and health relationships and our understanding of health inequalities.

Composite indicators, or indices, are used in other disciplines to present information from multiple variables in an understandable and usable form [4]. A UK example is the Carstairs score [5], which summarises four elements of multiple socioeconomic deprivation: material possessions, employment, living conditions and social class. Socioeconomic deprivation indices such as the Carstairs score are widely used in epidemiology, and have greatly facilitated research into the relationships between socioeconomic deprivation and health [6].

There is a growing need for measures that summarise environmental influences on health in a meaningful way, in order to inform policy-making and interventions [4]. Environmental summary measures have been trialled elsewhere (e.g., $[7,8])$, but none have sought to summarise multiple environmental deprivation in a specifically health-relevant way. A carefully constructed measure summarising health-relevant aspects of the physical environment could help improve our understanding of the importance of environmental determinants of health.

Our larger project aimed to quantify the overall healthrelated environmental burden faced by a population, by developing a health-based summary measure of multiple physical environmental deprivation for the UK and determining its utility. Here we describe the first stage of the project, in which we aimed to identify health-relevant dimensions of physical environmental deprivation and acquire suitable environmental datasets. Due to word constraints we summarise key decisions made and our justification for them. We also present the results of this process: an evidence-based list of environmental dimensions with population health relevance for the UK, and the spatial datasets we obtained and processed to represent these dimensions. Subsequent methodological steps, analysis and interpretation that builds on the work described here will be presented elsewhere.

\section{Methods \\ Stage I: Identifying health-relevant dimensions of environmental deprivation}

A summary measure of health-related physical environments should include only factors with a clear association with health [4], and to which substantial numbers of people are exposed. We therefore began by identifying distinct dimensions of physical environmental deprivation that were public health-relevant and quantifiable for the UK. A crucial first step was defining the 'physical environment': we decided to include external physical, chemical and biological factors and exclude social and cultural factors.
We documented the reasons for decisions made during the process in order to maximise transparency and promote replicability. We initially conducted a scoping review to guide selection of health-relevant environmental factors. To avoid overlooking less commonlyresearched factors we consulted a diverse range of sources. A long list of potentially relevant environmental factors was produced using a wide range of international academic and grey literature and by browsing titles returned from general 'environment + health' searches of publication databases (PubMed, WebOfKnowledge and GeoBase). For public health relevance we required that at least $10 \%$ of the UK population was exposed to each environmental factor; the factors for which this threshold would not be met were excluded.

We then systematically searched publication databases for empirical studies that had explored the health impacts of one or more environmental factors on the long list. Search terms were derived from the long list. The WebOfKnowledge database allowed us to order search results by citation scores, ensuring that key references were not overlooked. Additionally, reference lists of papers were manually browsed to locate further studies. Non-English language studies and those pre-1980 were excluded. Searching was halted for each environmental factor when a saturation point was reached, i.e., when no novel results were being returned.

The assembled evidence was appraised by the project team during group discussions, based on prevalence of the health outcome(s), rigour of the study design, and the strength of association established. Spatial datasets were sought to enable assessment of population exposure to factors when exceedance of the $10 \%$ threshold was not apparent from the literature. The end-product of this stage was a wish-list of health-relevant environmental factors we would want to include in our summary measure.

\section{Stage 2: Dataset acquisition and processing}

To maximise future utility and reproducibility of the measure the datasets used would ideally be readily available, routinely updated, representative of the environmental factors of concern and of an acceptable and comparable quality $[7,9]$. For each environmental factor on our wish-list we therefore sought data that were spatially contiguous, comprehensive across the UK and centred around 2001, to correspond with the decennial census which would be our source of denominator data for subsequent testing of the summary measure's utility. The environmental data needed to be fit for the purpose of reliably representing long-term exposure to each factor.

We selected UK 2001 Census Area Statistics (CAS) wards as our geographical unit of analysis. There were 10,654 
CAS wards in the UK at the 2001 census, with an average population of approximately 5,500. Using the geographical information system software ArcMap (ESRI Inc., Redlands, CA) we rendered each environmental dataset to the 2001 CAS wards.

\section{Results}

We long-listed 13 environmental factors and appraised the evidence for i) their association with health outcomes using the international literature and ii) their relevance to population health in the UK context. Consequently, seven factors were included in our wish-list for our summary measure of environmental deprivation (Table 1). Table 1 briefly outlines some key epidemiological evidence for

Table I: Summary justification for the environmental factors selected for our wish-list, including examples of typical effect sizes.

\begin{tabular}{l} 
Environmental factor \\
\hline Outdoor ambient air pollutants \\
Elevated risks of respiratory disease (RD), cardiovascular disease (CVD) \\
and total mortality consistently associated with air pollutants, at \\
concentrations frequently experienced in urban settings [II-I $]$. Evidence \\
of health effects strongest for particulate matter $\left(\mathrm{PM}_{10}\right)$ and ozone $\left(\mathrm{O}_{3}\right)$, \\
but also substantial for carbon monoxide (CO), sulphur dioxide $\left(\mathrm{SO}_{2}\right)$ and \\
nitrogen dioxide $\left(\mathrm{NO}_{2}\right)$.
\end{tabular}

Climate

Increased risks of CVD, RD and total mortality with both elevated and reduced temperatures found in many studies. [18-20]. Small but persistent elevations in risk are seen with each incremental deviation away from the UK's comfort temperature of $20^{\circ} \mathrm{C}$ [20], hence the entire population are exposed.

\section{Examples of typical risks reported $(+95 \% \mathrm{CI})$}

Meta-analysis all-cause mortality RR for $10 \mu \mathrm{g} \cdot \mathrm{m}^{-3}$ increase in pollutant

[I7]:

$P M_{10}=1.006$ ( 1.004 to 1.008 ) (33 studies)

$\mathrm{O}_{3}=1.003$ (I.00I to I.004) (15 studies)

Meta-analysis \% excess mortality for stated increase [I I]:

$\mathrm{CO}=1.7$ (I.2 to 2.2 ) for I.I Ppm increase (22 effect estimates)

$\mathrm{SO}_{2}=0.9$ (0.7 to I.2) for $9.4 \mathrm{ppb}$ increase (46 effect estimates)

$\mathrm{NO}_{2}=2.8$ (2.I to 3.5) for $24.0 \mathrm{ppb}$ increase (32 effect estimates)

\section{RD mortality:}

Cold: Six European country study, $2.46 \%(1.8 \mathrm{I}$ to 3.12$)$ increase per $1{ }^{\circ} \mathrm{C}$ drop below $18^{\circ} \mathrm{C}[21]$

Heat: The Netherlands, $10.4 \%$ (0.0 to 20.8$)$ increase per $1{ }^{\circ} \mathrm{C}$ increase

above $16.5^{\circ} \mathrm{C}[22]$

London, $5.44 \%$ ( 1.92 to 9.09 ) increase per $1^{\circ} \mathrm{C}$ increase above $23^{\circ} \mathrm{C}$ [23]

\begin{abstract}
Solar ultraviolet (UV) radiation
UV radiation is the main risk factor for skin cancer [24,25], but a consistent protective effect of UV (via vitamin D production) has been found against a number of more prevalent cancers [25-27]. All studies on prostate, breast and ovarian cancer that were systematically reviewed by van der Rhee et al. [26] showed a significant inverse relationship between sunlight and mortality/incidence. Most of the UK population experience some vitamin $D$ deficiency in winter because of inadequate exposure to solar UV [28].
\end{abstract}

Skin cancer: summary OR (29 studies) for maximally exposed subjects (non-occupational exposure) $=$ I.7I (I.54 to I.90) [24]

Mortality OR for high vs. low sunlight exposure [29]:

Prostate cancer 0.90 (0.87 to 0.93$)$ ( 97,873 cases)

Breast cancer 0.74 (0.72 to 0.76$)$ (I30,26I cases)

Ovarian cancer 0.84 (0.8I to 0.88$)(39,002$ cases $)$

Colon cancer 0.73 ( 0.71 to 0.74$)$ ( 153,51 I cases)

Industrial facilities

There is evidence that residence within $4 \mathrm{~km}$ of waste management sites or within $1.6 \mathrm{~km}$ of metal production/processing plants increases some cancer risks [e.g., [30-32]]. Evidence was inconsistent for refineries and combustion installations, and weak or non-existent for other facilities, therefore we included only waste management and metal production/ processing sites. Analysis using a geographical information system (GIS) revealed that $21 \%$ of the UK population resided within the relevant effect buffers reported for these sites.

\section{Within approx. $1.6 \mathrm{~km}$ of metal works:}

$\mathrm{HR}$ all-cause mortality for boys resident $\geq 10 \mathrm{yr}=1.52$ (significantly elevated) [33]

RR lung cancer mortality (vs. $>6 \mathrm{~km})=5.0$ (1.4 to 17.8) [32]

Cancer incidence RR within approx. $4 \mathrm{~km}$ of waste site (vs. low exposure):

Non-Hodgkin's lymphoma $=2.3$ (I.4 to 3.8) [34]

Stomach cancer $=1.27(1.04$ to 1.55$)[30]$

Green space

There is evidence that more natural environments have a beneficial effect on people's self-perceived health, blood pressure, levels of overweight and obesity and total mortality risks [35-42]. Population exposure to green space varies markedly across the UK and there is no indication of a minimum threshold for health.

IRR for high vs. low green space exposure [39]

All-cause mortality 0.94 (0.93 to 0.96$)$

Circulatory disease mortality 0.96 (0.93 to 0.99$)$
Drinking water quality

Disinfection By-Products (DBPs) have been consistently associated with a small elevated risk of bladder cancer, the fourth most common cancer in the UK $[43,44]$. Most of the UK population is exposed to disinfected drinking water.
Meta-analysis OR for cancer incidence (vs. low exposure):

Bladder cancer = I.I (I.0 to I.2) for intermediate exposure and I.4 (I.2 to

I.7) for long-term exposure ( $>40$ years) (8 studies) [44]

All cancer $=1.15$ (1.09 to I.20) for high exposure (12 studies) [43]
Noise
Strong associations found with ischaemic heart disease and hypertension,
both of which increase mortality risk [45].
Meta-analysis RR for $5 \mathrm{~dB}(\mathrm{~A})$ increase in noise [45]

Hypertension with occupational noise $=1.14$ (I.0I to I.29)

Hypertension with air traffic noise $=1.26$ (I.14 to I.39)

Ischaemic heart disease with road traffic noise $=1.09$ (I.05 to I.I3)

$\mathrm{Cl}=$ confidence interval, $\mathrm{HR}=$ hazards ratio, $\mathrm{IRR}=$ incidence rate ratio, $\mathrm{OR}=$ odds ratio, $\mathrm{RR}=$ relative risk . 
Table 2: Summary justification for the environmental factors considered but excluded from our wish-list.

Environmental factor

Extremely Low Frequency (ELF) radiation (power lines)

Studies find elevated rates of childhood leukaemia, the most common childhood cancer, with effects seen within $600 \mathrm{~m}$ of power lines [43,44,46].

Analysis of the National Grid for England and Wales (using GIS) revealed $<8 \%$ population exposure within $600 \mathrm{~m}$.

Radio Frequency (RF) radiation (radio and TV transmitters)

Inconsistent evidence for cancer effect [47]. Effects found within $10 \mathrm{~km}$ of the most powerful transmitters [48], of which there are approximately 20 in the UK. Population exposure $<10 \%$.

Radon

Strong evidence found for association with lung cancer [49,50], and an estimated $9 \%$ of lung cancer cases in Europe are attributable to radon exposure [49]. However, datasets for different regions of the UK have been prepared using different methodologies and at different resolutions, and population exposure to radon levels above the Action Level of $200 \mathrm{~Bq} / \mathrm{m}^{3}$ in England and Wales (highest resolution data) is < 4\% (our own GIS analysis).

Individual industrial pollutants

Although there is evidence for the health effects of acute (accidental or occupational) exposure to specific hazardous chemicals [5I], there is little or no evidence for their health effects at environmental levels.

Nuclear facilities

Evidence for an association with health is inconsistent and not strong [52,53]. A small proportion of the population lives in the proximity of the UK's 27 nuclear installations.

\section{Contaminated land}

The primary route of exposure for many soil contaminants is consumption of soil or contaminated vegetables [54], so << $10 \%$ population exposure. Mapping contaminated land for the UK is incomplete [55], and modelling human exposure to contaminants in soil is a highly complex process [56].

the health associations of each wish-listed factor (from meta-analyses where available), although the full evidence review for each factor was more comprehensive than can be reported here. Six environmental factors were excluded (Table 2) as a result of this evidence appraisal process.
We attempted to obtain UK-wide datasets representative of the environment in 2001 (the date for which reliable population data are available) for the seven wish-listed factors. However, data reliability and availability issues meant that we were unable to obtain suitable information pertaining to drinking water quality and noise. For the five remaining environmental factors, the UK-wide datasets

Table 3: Details of the datasets acquired and ward-level measures derived for the key environmental factors.

\begin{tabular}{|c|c|c|c|}
\hline Key factor & Specific aspect & Data source & Ward-level measure derived \\
\hline Air pollution & $\begin{array}{l}\text { Particulate matter }\left(\mathrm{PM}_{10}\right) \\
\text { Ozone }\left(\mathrm{O}_{3}\right) \\
\text { Nitrogen dioxide }\left(\mathrm{NO}_{2}\right) \\
\text { Sulphur dioxide }\left(\mathrm{SO}_{2}\right) \\
\text { Carbon monoxide }(\mathrm{CO})\end{array}$ & $\begin{array}{l}\text { AEA Technology (I km grids, annual average } \\
\text { concentrations, modelled from National } \\
\text { Atmospheric Emissions Inventory (NAEI) data, } \\
\text { 1999-2006) }\end{array}$ & $\begin{array}{l}\text { Population-weighted average of each pollutant } \\
\text { (averaged I } 999 \text { to } 2003 \text { for all except CO: } 200 \text { I } \\
\text { to 2006) }\end{array}$ \\
\hline Climate & $\begin{array}{l}\text { Average temperature } \\
\text { Cooling degree-days }{ }^{1} \\
\text { Heating degree-days }{ }^{2} \\
\text { Winter coldwave duration }{ }^{3} \\
\text { Summer heatwave duration } 4\end{array}$ & $\begin{array}{l}\text { Meteorological Office UK Climate Impact } \\
\text { Programme data ( } 5 \mathrm{~km} \text { grids, 1996-2003) }\end{array}$ & $\begin{array}{l}\text { Population-weighted average of each climate } \\
\text { variable } \\
\text { (averaged I999 to 2003, except for coldwaves } \\
\text { and heatwaves: 1996-2000) }\end{array}$ \\
\hline UV radiation & - & $\begin{array}{l}\text { UVB Index [57] calculated using Meteorological } \\
\text { Office monthly cloud cover data (I km grid, } \\
\text { |99|-2000) and latitude }\end{array}$ & $\begin{array}{l}\text { Population-weighted average UVBI } \\
(1991 \text { - 2000) }\end{array}$ \\
\hline Industrial facilities & $\begin{array}{l}\text { Waste management sites } \\
\text { Metal production/processing sites }\end{array}$ & $\begin{array}{l}\text { European Pollutant Emission Register (EPER) } \\
\text { (grid references, 200I-2002) }\end{array}$ & $\begin{array}{l}\text { Proportion of population living within } 4 \mathrm{~km} \text { of } \\
\text { waste site or } 1.6 \mathrm{~km} \text { of metal site } \\
(2001-2002)\end{array}$ \\
\hline Green space & - & $\begin{array}{l}\text { Generalised Land Use Database (GLUD, } \\
\text { England only, 200I) and Coordination of } \\
\text { Information on the Environment (CORINE) } \\
\text { Land Cover Data (UK, 2000) }\end{array}$ & $\begin{array}{l}\text { Modelled GLUD \% green space using CORINE } \\
\text { variables and population density }(200 \mathrm{I})\left(\mathrm{R}^{2}=\right. \\
0.95) \text {, then used model to predict } \% \text { green space } \\
\text { for whole UK }\end{array}$ \\
\hline
\end{tabular}

\footnotetext{
I no. of degree-days above $22^{\circ} \mathrm{C}$

2 no. of degree-days below $15.5^{\circ} \mathrm{C}$ in winter months

3 no. of days with daily minimum $>3^{\circ} \mathrm{C}$ below 196I-90 daily normal for $\geq 5$ consecutive days (Nov-Apr)

${ }^{4}$ no. of days with daily maximum $>3^{\circ} \mathrm{C}$ above 196I-90 daily normal for $\geq 5$ consecutive days (May-Oct)
} 
obtained and the ward-level measures derived from these data are detailed in Table 3. Mapping each measure in a geographical information system (GIS) (Figure 1) confirmed that the datasets represented expected geographical trends (e.g., higher pollution in urban areas, and higher average temperatures towards the south and east).

\section{Discussion}

We aimed to identify health-relevant dimensions of physical environmental deprivation and acquire suitable environmental datasets. Guided by accepted principles for the design of composite indicators [4], we have documented the rationale behind our decisions throughout, to ensure transparency and repeatability.

The summary measures we will create and test during subsequent phases of the project will only be as good as the datasets we have used, hence we sought the most reliable data available. We were only able to obtain reliable and contiguous data for five of the seven environmental factors on our wish-list, but the list remains as a useful byproduct of the process. The excluded wish-list factors (drinking water quality and noise) could be included in future attempts at summarising multiple environmental deprivation should suitable datasets become available. Furthermore, based on evidence of effect size we judged that the health impacts of the two excluded factors were unlikely to be as substantial as, say, air pollution, and hence anticipated that a useful composite indicator could be constructed using the remaining five factors.

Additionally, the acquired datasets had limitations. To ensure the future utility and replicability of the work we prioritised datasets that were readily available and likely to be routinely updated in the future. The pollutant and meteorological datasets selected for meeting these criteria were relatively coarse grids ( 1 and $5 \mathrm{~km}$ ), therefore they may not adequately represent individual-level exposure in
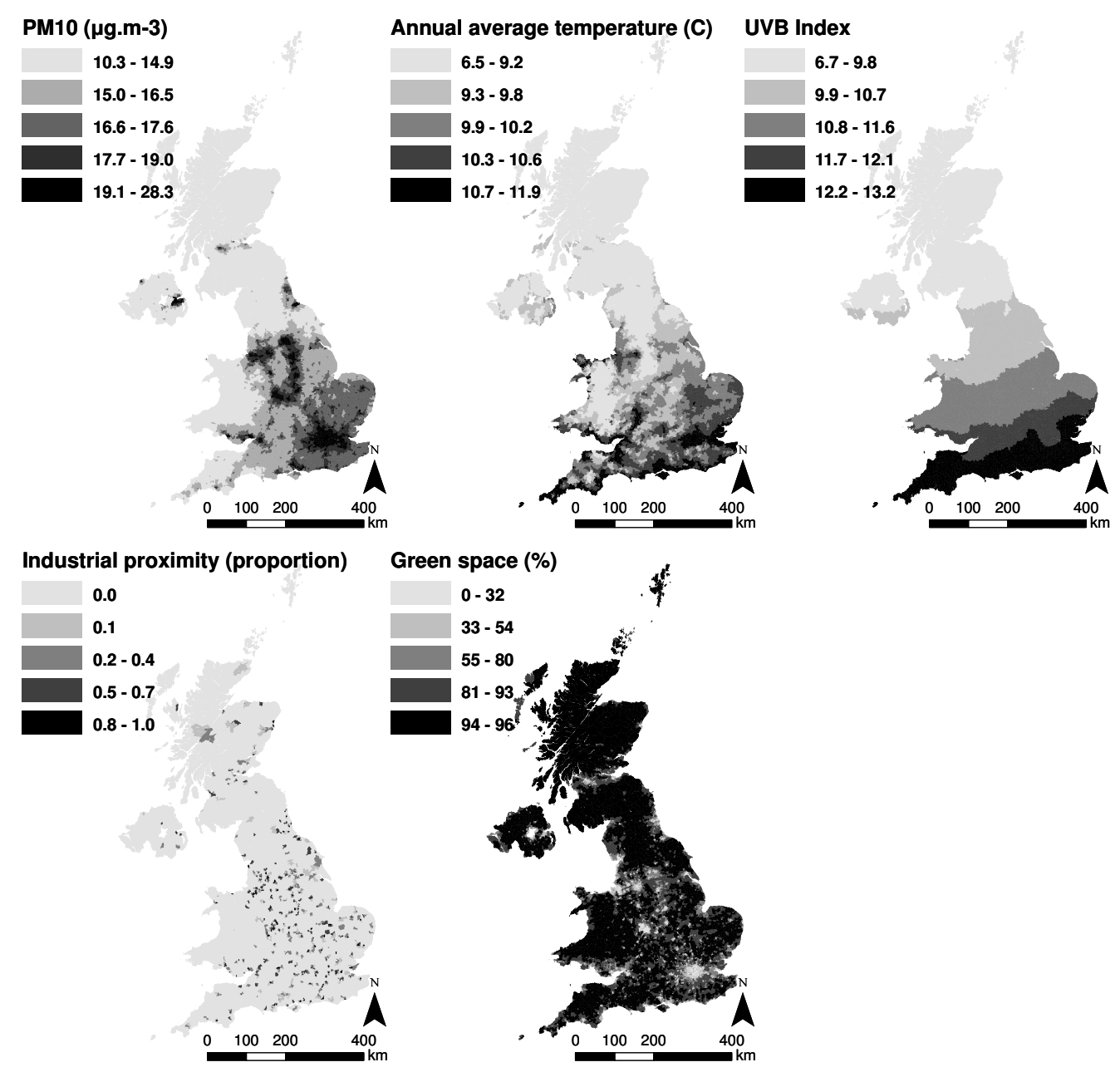

Figure I

Ward-level measures of the environmental factors, separated into equal quintiles (by number of wards). 
each ward. Although finer resolution data may have helped alleviate these exposure misclassification issues it is less likely that any such data, if available, would be readily available for the whole $\mathrm{UK}$ and/or routinely updated.

The preparation of separate datasets by the four countries of the UK, sometimes to different standards, also proved problematic. In particular the detailed land use mapping product (Generalised Land Use Database, GLUD) was only available for England, whereas the coarser resolution dataset (Coordination of Information on the Environment, CORINE) was available for the whole UK. For industrial facility locations the readily available EPER database (EU-wide) usefully combined all UK data. Whilst this circumvented the need for us to acquire different datasets from separate organisations, and would aid future reproducibility of the work, EPER data from the first reporting year (2001) are known not to be fully comprehensive for all facilities in all countries [10]. Future work may therefore have more comprehensive data to incorporate.

Where necessary our environmental datasets were averaged to give an indication of long-term exposure in each ward. However, short-term variations in some environmental factors have health-relevance (e.g., air pollutant peaks, extreme low temperature events). Implicit in our approach, therefore, is the assumption that the severity of the short-term extremes correlates well with longer-term averages.

\section{Conclusion}

We have demonstrated that it is possible to identify health-relevant dimensions of the physical environment and acquire suitable datasets to represent variation in these dimensions across the UK. In doing so we have laid the foundations for the rest of the project: constructing a summary measure of multiple environmental deprivation for the UK and determining its utility in researching spatial inequalities in health. The process and its limitations have been transparently described, to aid further work and the informed use of its outputs.

\section{List of abbreviations used}

AEA: Atomic Energy Authority; CA: California State; CAS: Census Area Statistics; CI: Confidence interval; CORINE: Coordination of Information on the Environment; CVD: Cardiovascular disease; DBP: Disinfection By-Products; ELF: Extremely Low Frequency radiation; EPER: European Pollutant Emission Register; ESRI: Environmental Systems Research Institute; EU: European Union; GIS: Geographical Information System; GLUD: Generalised Land Use Database; HR: Hazards ratio; NAEI: National Atmospheric Emissions Inventory; OR: Odds ratio; RD: Respira- tory disease; RF: Radio Frequency radiation; RR: Relative risk; UK: United Kingdom; UV: Ultraviolet.

\section{Competing interests}

The authors declare that they have no competing interests.

\section{Authors' contributions}

ER prepared the reviews and drafted the manuscript. ER acquired and processed datasets, assisted by TD. RM conceived of the study. All authors helped collate literature. All authors participated in design and coordination of the study, and helped review the empirical evidence. All authors read and approved the final manuscript.

\section{Note}

The peer review to this article can be found in Additional file 1.

\section{Additional material}

Additional file 1
Peer review.
Click here for file
[http://www.biomedcentral.com/content/supplementary/1476-
069X-8-S1-S18-S1.doc]

\section{Acknowledgements}

We would like to thank two anonymous reviewers for their constructive comments. The work was supported by the Joint Environment \& Human Health Programme (NERC, EA, Defra, MOD, MRC, The Wellcome Trust, ESRC, BBSRC, EPSRC and HPA), grant number NE/E008720/2.

This article has been published as part of Environmental Health Volume 8 Supplement I, 2009: Proceedings of the Joint Environment and Human Health Programme: Annual Science Day Conference and Workshop. The full contents of the supplement are available online at http://www.ehjour nal.net/supplements/8/SI.

\section{References}

I. Finkelstein MM, Jerrett M, Sears MR: Environmental inequality and circulatory disease mortality gradients. J Epidemiol Community Health 2005, 59(6):48I-487.

2. Evans GW, Kantrowitz E: Socioeconomic status and health: the potential role of environmental risk exposure. Annual Review of Public Health 2002, 23:303-33I.

3. Sterner O: Chemistry, Health and Environment Weinheim: Wiley-VCH; 1999.

4. Corvalán $C$, Briggs $D$, Kjellström $T$ : The need for information: environmental health indicators. In Decision-Making In Environmental Health Edited by: Corvalán C, Briggs D, Zielhuis G. London: E \& FN Spon; 2000:25-56.

5. Carstairs V, Morris R: Deprivation: explaining differences in mortality between Scotland and England and Wales. Br Med J 1989, 299:886-889.

6. Carstairs V: Deprivation indices: their interpretation and use in relation to health. J Epidemiol Community Health 1995, 49:S3-S8.

7. Sol VM, Lammers PEM, Aiking H, de Boer J, Feenstra JF: Integrated environmental index for application in land-use zoning. Env Manag 1995, 19(3):457-467. 
8. Wheeler BW: Health-related environmental indices and environmental equity in England and Wales. Environ Plan A 2004, 36:803-822.

9. Nardo M, Saisana M, Saltelli A, Tarantola S, Hoffman A, Giovannini E: Handbook On Constructing Composite Indicators: Methodology And User Guide. 2008 [http://browse.oecdbookshop.org/ oecd/pdfs/browseit/300825IE.PDF]. EC Joint Research Centre \& OECD Statistics Directorate and the Directorate for Science, Technology and Industry

10. Questions to EPER [http://eper.ec.europa.eu/eper/faq.asp?i=]

1I. Stieb DM, Judek S, Burnett RT: Meta-analysis of time-series studies of air pollution and mortality: effects of gases and particles and the influence of cause of death, age, and season. J Air Waste Manag Assoc 2002, 52(4):470-484.

12. Bell ML, Dominici F, Samet JM: A meta-analysis of time-series studies of ozone and mortality with comparison to the national morbidity, mortality, and air pollution study. Epidemiology 2005, I 6(4):436-445.

13. Ito K, De Leon SF, Lippmann M: Associations between ozone and daily mortality: analysis and meta-analysis. Epidemiology 2005 I 6(4):446-457.

14. Levy JI, Hammitt JK, Spengler JD: Estimating the mortality impacts of particulate matter: what can be learned from between-study variability? Environ Health Perspect 2000, 108(2):109-117.

15. Schwartz J: Air pollution and daily mortality: a review and meta analysis. Environ Res 1994, 64(1):36-52.

16. World Health Organization: Health aspects of air pollution: results from the WHO project "Systematic review of health aspects of air pollution in Europe". Geneva: World Health Organization; 2004.

17. World Health Organization: Meta-analysis of time-series studies and panel studies of particulate matter (PM) and ozone (O3). Geneva: World Health Organization; 2004.

18. Basu R, Samet JM: Relation between elevated ambient temperature and mortality: a review of the epidemiologic evidence. Epidemiol Rev 2002, 24(2): 190-202.

19. Curriero FC, Heiner KS, Samet JM, Zeger SL, Strug L, Patz JA: Temperature and Mortality in II Cities of the Eastern United States. Am J Epidemiol 2002, I 55(I):80-87.

20. Martens WJ: Climate change, thermal stress and mortality changes. Soc Sci Med 1998, 46(3):331-344.

21. The Eurowinter Group: Cold exposure and winter mortality from ischaemic heart disease, cerebrovascular disease, respiratory disease, and all causes in warm and cold regions of Europe. Lancet 1997, 349(9062): |34|-1346.

22. Kunst AE, Looman CWN, Mackenbach JP: Outdoor air temperature and mortality in the Netherlands: a time-series analysis. American Journal of Epidemiology 1993, 137(3):331-341.

23. Kovats RS, Hajat S, Wilkinson P: Contrasting patterns of mortality and hospital admissions during hot weather and heat waves in Greater London, UK. Occupational and Environmental Medicine 2004, 6 I ( I I):893-898.

24. Elwood JM, Jopson J: Melanoma and sun exposure: an overview of published studies. International Journal of Cancer 1997 73:198-203.

25. Reichrath J: The challenge resulting from positive and negative effects of sunlight: how much solar UV exposure is appropriate to balance between risks of vitamin $D$ deficiency and skin cancer? Progress in Biophysics and Molecular Biology 2006, 92(I):9-16.

26. van der Rhee HJ, de Vries E, Coebergh JW: Does sunlight prevent cancer? A systematic review. European Journal of Cancer 2006 42(1 4):2222-2232.

27. Krause R, Matulla-Nolte B, Essers M, Brown A, Hopfenmüller W: UV radiation and cancer prevention: what is the evidence? Anticancer Res 2006, 26(4A):2723-2727.

28. Gillie O: Sunlight robbery: health benefits of sunlight are denied by current public health policy in the UK. 2004 [http:/ /www.healthresearchforum.org.uk/reports/sunlightrobbery.pdf]. Health Research Forum Accessed 8 January 2008.

29. Freedman DM, Dosemeci M, McGlynn K: Sunlight and mortality from breast, ovarian, colon, prostate, and non-melanoma skin cancer: a composite death certificate based case-control study. Occupational and Environmental Medicine 2002, 59(4):257-262.
30. Goldberg MS, Al-Homsi N, Goulet L, Riberdy H: Incidence of cancer among persons living near a municipal solid waste landfill site in Montreal, Quebec. Arch Environ Health 1995 , 50(6):416-424.

31. Smith GH, Williams FL, Lloyd OL: Respiratory cancer and air pollution from iron foundries in a Scottish town: an epidemiological and environmental study. $\mathrm{Br} J$ Ind Med 1987 44( I 2):795-802.

32. Brown LM, Pottern LM, Blot W]: Lung cancer in relation to environmental pollutants emitted from industrial sources. Environ Res 1984, 34:250-26I.

33. Tollestrup K, Frost F], Harter LC, McMillan GP: Mortality among children residing near the American Smelting and Refining Company (ASARCO) copper smelter in Ruston, Washington. Arch Environ Health 2003, 58(I I):683-69I.

34. Floret N, Mauny F, Challier B, Arveux P, Cahn JY, Viel JF: Dioxin emissions from a solid waste incinerator and risk of nonHodgkin lymphoma. Epidemiology 2003, I4(4):392-398.

35. Maas J, Verheij RA, Groenewegen PP, de Vries S, Spreeuwenberg P: Green space, urbanity, and health: how strong is the relation? J Epidemiol Community Health 2006, 60:587-592.

36. de Vries S, Verheij RA, Groenewegen PP, Spreeuwenberg P: Natural environments - Healthy environments? An exploratory analysis of the relationship between greenspace and health. Environ Plan A 2003, 35(1 0): I7| 7-I73|.

37. Sugiyama T, Leslie E, Giles-Corti B, Owen N: Associations of neighbourhood greenness with physical and mental health: do walking, social coherence and local social interaction explain the relationships? J Epidemiol Community Health 2008, 62(5):e9.

38. Takano T, Nakamura K, Watanabe M: Urban residential environments and senior citizens' longevity in megacity areas: the importance of walkable green spaces. J Epidemiol Community Health 2002, 56(I 2):913-918.

39. Mitchell R, Popham F: Effect of exposure to natural environment on health inequalities: an observational population study. Lancet 2008, 372:1655-1660.

40. Mitchell R, Popham F: Greenspace, urbanity and health: relationships in England. J Epidemiol Community Health 2007, 6I (8):68I-683

41. Ellaway A, Macintyre S, Bonnefoy X: Graffiti, greenery, and obesity in adults: secondary analysis of European cross sectional survey. BMJ 2005, 33 I:6 I I-6I 2 .

42. Hartig T, Evans GW, Jamner LD, Davis DS, Gärling T: Tracking restoration in natural and urban field settings. J Environ Psychol 2003, 23:109-123.

43. Morris RD, Audet AM, Angelillo IF, Chalmers TC, Mosteller F: Chlorination, chlorination by-products, and cancer: a meta-analysis. Am J Public Health 1992, 82(7):955-963.

44. Villanueva CM, Fernandez F, Malats N, Grimalt JO, Kogevinas M: Meta-analysis of studies on individual consumption of chlorinated drinking water and bladder cancer. J Epidemiol Community Health 2003, 57(3): 166-173.

45. van Kempen EEMM, Kruize H, Boshuizen HC, Ameling CB, Staatsen $B A M$, de Hollander AEM: The association between noise exposure and blood pressure and ischaemic heart disease: a meta-analysis. Environ Health Perspect 2002, I I0(3):307-317.

46. Draper G, Vincent T, Kroll ME, Swanson J: Childhood cancer in relation to distance from high voltage power lines in England and Wales: a case-control study. $\mathrm{Br}$ Med J 2005, 330(7503): 1290

47. Feychting M, Ahlbom A, Kheifets L: EMF and health. Annual Review of Public Health 2005, 26:165-189.

48. Dolk H, Elliott P, Shaddick G, Walls P, Thakrar B: Cancer Incidence near Radio and Television Transmitters in Great Britain II. All High Power Transmitters. Am J Epidemiol 1997, 145(I): 10-17.

49. Darby S, Hill D, Auvinen A, Barros-Dios JM, Baysson H, Bochicchio F, Deo H, Falk R, Forastiere F, Hakama M, et al.: Radon in homes and risk of lung cancer: collaborative analysis of individual data from 13 European case-control studies. $\mathrm{Br}$ Med J 2005, 330(7485):223.

50. Pavia M, Bianco A, Pileggi C, Angelillo IF: Meta-analysis of residential exposure to radon gas and lung cancer. Bulletin of the World Health Organization 2003, 8 I ( I 0):732-738. 
5I. Harrison PTC: Health effects of environmental chemicals. In Pollution: Causes, Effects and Control Edited by: Harrison RM. Cambridge: The Royal Society of Chemistry; 200I.

52. Baker PJ, Hoel DG: Meta-analysis of standardized incidence and mortality rates of childhood leukaemia in proximity to nuclear facilities. European Journal of Cancer Care 2007 16(4):355-363.

53. Laurier D, Grosche B, Hall P: Risk of childhood leukaemia in the vicinity of nuclear installations--findings and recent controversies. Acta Oncologica 2002, 4 I (I): 14-24.

54. Gay JR, Korre A: A spatially-evaluated methodology for assessing risk to a population from contaminated land. Environmental Pollution 2006, I 42(2):227-234.

55. Fordyce FM, O'Donnell KE, Lister TR, Breward N, Johnson CC Brown SE, Ander EL, Rawlins BG: GSUE: Urban geochemical mapping in Great Britain. Geochemistry: Exploration, Environment, Analysis 2005, 5(4):325-336.

56. DEFRA and EA: Assessment of risks to human health from land contamination: an overview of the development of soil guideline values and related research. Bristol, UK: Environment Agency; 2002

57. Mo T, Green AES: A climatology of solar erythema dose. Photochem Photobiol 1974, 20:483-496.

Publish with Biomed Central and every scientist can read your work free of charge

"BioMed Central will be the most significant development for disseminating the results of biomedical research in our lifetime. "

Sir Paul Nurse, Cancer Research UK

Your research papers will be:

- available free of charge to the entire biomedical community

- peer reviewed and published immediately upon acceptance

- cited in PubMed and archived on PubMed Central

- yours - you keep the copyright 